\title{
Revenues from related Parties Transactions and UEFA Financial Fair Play. The Search for an Alternative Solution to Fair Value Measurement for the Break-even Result Assessment
}

\author{
By Salvatore Cincimino*
}

\begin{abstract}
Transactions with related parties (RPTs) are numerous and frequent in the economy of companies; they are often made with different values from the ones in arm's length transactions, and sometimes for opportunistic reasons. Many cases of RPTs occur in the football sector too, and they are mostly related to sponsorship contracts revenues. Through the financial fair play regulations, UEFA encourages the clubs which want to get the license for competing in European tournaments, to count on their capability to operate on the basis of their own revenues. The reorientation of the professional football clubs economic governance requested by UEFA also provides specific RPTs disclosure as well as their fair value measurement, suggesting downward adjustments for RPT revenues, and upward adjustments for RPT costs, recorded at different value. However, the procedures and activities underlying the fair value measurement expose to some difficulties - among which the need for specific individual decision on each case, with the consequent high risk of treating similar cases differently - and are likely to undermine the effectiveness of the financial fair play rules. This contribution suggests an alternative hypothesis with respect to fair value measurement of RPTs for the UEFA FFP.
\end{abstract}

\section{Introduction}

Commercial relations with related parties (RP) are numerous, different and frequent in the business of the companies.

It seems natural that a company prefers to do business with a supplier (for the acquisition of goods, services or financial resources) with whom it has a relationship of participation in share capital (subsidiary, associated entity, controlling entity), an agreement, or even if there is a family relationship between the owner/manager of the company and the supplier. The resulting related party transactions (RPTs) might however be made under (more or less favourable) conditions different from open market ones (above all: Cheung et al., 2009), with the consequence of influences/interferences on financial results (IAS 24, § 6) and firm value (Wong and Jian, 2003). RPTs can also be causes

*Assistant Professor of Business Administration, University of Palermo, Italy. 
of conflicts of interest compromising the shareholder's confidence in the management of the company (Gordon et al., 2004); they are still perceived as opportunistic (Wong and Jian, 2003) and they also entail the implementation and/or the audit of specific internal rules and procedures, such as the ethical codes of behaviour (above all: Handfield and Baumer, 2006).

It therefore become necessary to regulate the disclosure of financial statements on RPTs. Scholars become interested to the topic and the International Accounting Standards Board (IASB) issued a specific accounting standard, IAS 24.

RPTs are also frequent in the football sector. For example, it is known that chronic and structural economic losses incurred by professional football clubs (PFCs) are covered by contributions from the owners and/or RP.

In Europe, the recent UEFA rules on financial fair play (FFP) tend to radically affect the governance of PFCs, focusing on economic as well as at sport competition among clubs. In fact, clubs wishing to obtain a license to join the UEFA European competitions must now also demonstrate, in addition to other obligations, the achievement of adequate economic performance (so called break-even result, BER). For this reason, in order to remain competitive at sporting level, and to sustain the related high costs, PFCs are required to achieve sufficient revenues. It can therefore arise, among clubs, the temptation to inflate the revenue volume through specific RPTs. In this regard, UEFA regulates the assessment of RPTs, providing that the so-called recorded value should be reported at fair value. However, some RPTs, and specifically the sponsorship contracts, might escape to the effective system of rules of FFP. Sponsorship revenues from RP may in fact conceal a contribution to equity rather than a genuine provision of services, but it is very difficult to separate the equity amount from the actual revenue amount.

This paper deals with related parties transactions in the professional football sector and the difficulty to evaluate some of them - viz. revenues from sponsorship contracts - for the purposes of applying the rules of FFP. The contribution suggests an alternative measurement hypothesis with respect to fair value.

The paper is structured as follows. After a brief review of IAS 24 and a description of the symmetries with the UEFA rules about FFP, the discipline of financial statement disclosures of RPTs in Italy and the "state of the art" in terms of quality and quantity of these disclosures are analyzed, through the financial statements of PFCs who are active in the "Serie A" championship in Italy. The RPT discipline is then described in accordance with FFP rules and some critical issues regarding the measurement at fair value, with specific reference to revenues from RP sponsorship, are pointed out. Before conclusions, the analysis leads to an alternative proposal for the determination the value of revenues from RPTs. 


\section{Related Party Transaction: IAS 24 and UEFA FFP Regulations}

RPTs can be carried out at non-market values or at conditions different from those that would have been obtained between independent entities, with the consequence of distorted economic and financial results of the company. It is basically to ensure adequate transparency of these transactions that the International Accounting Standards Board (IASB) has regulated with a specific principle (IAS 24) the disclosure of companies (the so-called "reporting entity": RE) on RPTs. The criteria with which RE identify RPs, distinctly between "a person or a close member of that person's family" (IAS, $\S 9$. a) and "an entity ... related to a reporting entity" (IAS, § 9. b) are so broad that in IAS 24: a. specific "limits" are identified, beyond which the parties, despite possible relationships and agreements, shall not be considered to be related (IAS, § 11) b. however, substance of the relationships and agreements over form is preferred (IAS, $\S 10$ ).

Given the vagueness of the definition of RPT ("a transfer of resources, services or obligations between a reporting entity and a related party, regardless of whether a price is charged" - IAS $24, \S 9$ ), and the large number of IAS reported cases $(\S 21)$, it is evident that the RE has broad discretion in identifying RPs and describe RPTs. This is a very delicate and important issue. It is thus necessary that the RE give exhaustive information. In fact, the accuracy of voluntary information, even in the environmental field (Toms, 2002), or in forecasting records (Hutton and Stocken, 2009), is one of the underlying conditions of the company's reputation. In turn, the reputation of an entity is one of the determinants of its sustainability disclosure (Michelon, 2011). It is also significant to prefer qualitative to quantitative information (Hasseldine et al, 2005). It is therefore appropriate to pay adequate attention to quality issues, rather than to quantitative data, as required by paragraph 18 of IAS 24, separately for categories of RP (IAS 24, § 19). Paragraph 23 of IAS 24 also points out that "disclosures that related party transactions were made on terms equivalent to those that prevail in arm's length transactions are made only if such terms can be substantiated." In this regard, Christensen et al. (2012) show that the volatility of the estimate of RPTs may have substantial impact on the financial performance.

Setting strict rules and forecasting highly detailed information may however cause counterproductive effects in recipients of information (McCahery and Vermeulen, 2011). It is also shown that in terms of conflict of interest, paradoxically, "non-disclosure can have the positive effect of facilitating the formation of reputation" (Koch and Schmidt, 2010; also Cain et al, 2005), obviously as long as the conflict is not unveiled from external sources too, which is often the case in the areas constantly placed under the spotlight, which is the football sector.

In this respect UEFA, adopting the rules on FFP, gave particular importance to information on RPs, in order to make the management operations carried out by the clubs that require a license more comprehensible, as well as to proceed with any corrections, reporting at fair value the amounts 
by which such operations have been carried out (so called recorded value). The club (licensee) "must disclose the nature of the related party relationship, as well as information about those transactions and outstanding balances, including commitments, necessary for an understanding of the potential effect of the relationship on the financial statements", and also details about transactions and commitments with each related party (UEFA FFP Regulations, Annex VI, par. E.1.j)) ${ }^{1}$. The Annex X of the "UEFA Club Licensing and Financial Fair Play Regulations - Edition 2012" (UEFA FFP Regulations) fully retrieves certain paragraphs of the latest version of IAS 24, explained in table 1 .

Table 1. Links between IAS 24 and UEFA Club Licensing

\begin{tabular}{|lll|}
\hline Items & UEFA FFP Regulations & mention to IAS 24 \\
\hline RPT disclosures & Annex VI, § E.1.j) & $\S 18 . \S 23 . \S 24$. \\
\hline $\begin{array}{l}\text { RP, RPT and fair value } \\
\text { of RPT - definitions }\end{array}$ & Annex X, § E.1.2.3. & \\
& 4.5 .6 .7$. & $\S 9 . \S 10 . \S 11 . \S 12$. \\
\hline
\end{tabular}

\section{Related Party Transaction: National Accounting Standard and Quality of Disclosure in the Italian PFC}

Compared to what is required by IAS 24, and by UEFA, regulations on RPT disclosures in Italy require a lower degree of detail.

In fact, only for listed companies and for the companies issuing shares widely distributed among the public in a significant way, and only trough the legislative decree no. 310/2004 (in force since 14 January 2005) the article 2391-bis was introduced in the Civil Code, which states that management must arrange and adopt specific rules (viz. real internal codes of conduct) to ensure transparency and substantive and procedural fairness of RPTs to be reported to the management report. Internal rules should be prepared by each company on the basis of the general principles of the National Commission for the Companies and the Stock Exchange - CONSOB, an independent national body whose activities are aimed at investor protection, and at efficiency and transparency of the Italian securities market. A generic mention to RPs is included in the Italian Accounting Principle OIC 1 (October 2004, 57-58) that resumes the CONSOB rules. Also the appendix to OIC 1 (May 2005 6-8) appreciates the introduction of the article 2391-bis of the civil code.

For all companies, the Civil Code (Article 2427) provides that the notes to the accounts contain information about the relationships with subsidiaries, associated parent companies and others. Only the Legislative Decree no. $173 / 2008$ (mandatory for the companies in the reporting periods ending after 21 November 2008) introduced the point 22-bis in article 2427 of the Civil

\footnotetext{
${ }^{1}$ According to UEFA FFP Regulations, the PFC must also: a. set out in the balance sheet the items regarding RPTs (Annex VI); b. disclose information on RP contributions useful for the calculation of the acceptable deviation (Article 61 and Annex X); adjust the recorded value of revenues and expenses of any transaction with RP to fair value (Article 58, par. 4), for the correct calculation of the BER (Annex X).
} 
Code, in which the company must indicate transactions with RPs, specifying the amount, the nature of the relationship and any other information necessary for an understanding of the financial statement relating to such transactions, but only in cases they are relevant and have not been concluded under normal market conditions. Information relating to individual transactions may be aggregated according to their nature except when it is necessary, for clarity purposes, to have separate disclosures.

Only relevant information on RPTs should therefore be disclosed, and not arm's length ones. In this regard, the CONSOB issued specific regulations identified quantitative indicators and a qualitative criterion ${ }^{1}$. The appendix to the Italian Accounting Principle OIC 12 (March 2010, 3-6, 9) examines in detail the contents of the point in the article 22-bis 2427.

Compared to what is regulated by IAS 24, the following considerations may be made with regard to disclosure on the RPTs in Italy: - except for the information on transactions with subsidiaries/affiliates/parent companies, RPT regulations are fairly recent, and refer to generic criteria (as in the case of the identification of relevant transactions); - the decision-making center of gravity for the identification, investigation and approval of RPTs is shifted towards the companies, which must themselves define specific self-government procedures; - however, regulations are detailed for listed companies (in football: only Juventus, Lazio, Roma), and not for all companies. The not listed companies (all the others PFCs) experience many difficulties and, in the absence of specific provisions (moreover, self-government procedures for listed companies are expensive) they limit, or omit, information.

A general carelessness thus appears in disclosures that instead, especially for the PFCs, should be properly made. A specific analysis conducted on the financial statements of the PFCs that in the seasons 2008/09, 2009/10, 2010/11 have played in the championship Serie A, summarized in table 2, reveals the effects of jagged and uneven regulations, confirming the claims made by Berglöf and Pajuste (2005), regarding the different level of disclosure across firms, and the strong country effect in what companies disclose.

\footnotetext{
${ }^{1}$ RPTs are relevant if the relationship between the following components is greater than $5 \%$ (or $2.5 \%$ in specific cases): a. the value of the RPT and the average market capitalization for the last 6 months of the shares of the company; b. total value of RPT asset's and total assets of the company; c. pre-tax profits attributable to RPT and pre-tax profits of the company; $d$. total liabilities of the RPT and total assets of the company; e. the amount of the RPT and the revenues of the company. Should also be considered relevant the RP operations "unusual and infrequent" (qualitative criterion).
} 
Table 2. RPTs disclosure in financial statements of Serie A PFCs

\begin{tabular}{|lrrr|}
\hline & $\mathbf{2 0 0 8 / 0 9}$ & $\mathbf{2 0 0 9 / 1 0}$ & $\mathbf{2 0 1 0 / 1 1}$ \\
\cline { 2 - 4 } & $\mathbf{2 0}$ & $\mathbf{2 0}$ & $\mathbf{2 0}$ \\
Total absence of information on RPT & $\mathbf{4}$ & $\mathbf{2}$ & $\mathbf{1}$ \\
Total absence of information on RPT in the Notes to & & & \\
accounts (basic information in the Management report) & $\mathbf{1 1}$ & $\mathbf{7}$ & $\mathbf{6}$ \\
Information minimized and generic & $\mathbf{6}$ & $\mathbf{3}$ & $\mathbf{4}$ \\
Information on member of the same group & $\mathbf{2 0}$ & $\mathbf{1 9}$ & $\mathbf{2 0}$ \\
Relationships with managers & $\mathbf{3}$ & $\mathbf{3}$ & $\mathbf{3}$ \\
Report about significant transactions: & $\mathbf{1 9}$ & $\mathbf{1 8}$ & $\mathbf{1 8}$ \\
- not relevant or in arm's length & $\mathbf{6}$ & $\mathbf{8}$ & $\mathbf{9}$ \\
- conditions of reciprocal economic gain & $\mathbf{1}$ & $\mathbf{2}$ & $\mathbf{1}$ \\
- substantive and procedural fairness & $\mathbf{1}$ & $\mathbf{1}$ & $\mathbf{1}$ \\
Remeasurement to fair value & - & - & - \\
\hline
\end{tabular}

What the analysis points out better is the extreme delicacy with which one should address the difficult issue of downward adjustments (for revenues) and upward adjustments (for costs) which the clubs of all UEFA member countries requiring a license must work to bring the recorded value of the RPTs to fair value, and thus the identification of the RPTs fair value.

\section{Revenues from Related Party Transactions in PFCs: sponsorship contracts with RPs and fair value assessment}

According to UEFA FFP Regulations, article 58, paragraph 4, "relevant income and expenses from related parties must be adjusted to reflect the fair value of any such transactions" The algebraic sum of relevant income and relevant expenses, namely the BER, is the economic data for defining the eligibility of a club to obtain UEFA license (UEFA FFP, Regulations, articles 53-68).

Annex $X$ of the UEFA FFP Regulations clarifies that "the club must determine the fair value of any related party transaction(s)". The club must carry out a verification of each RPT, reducing the value of a revenue from RPT (downward adjustment) and increasing the value of a cost (upward adjustment), if "the estimated fair value is ... (lower than) the recorded value". An example is shown in table 3.

Table 3. Examples of down- and upward adjustments of RPTs

\begin{tabular}{|lr|r|ll|}
\hline Incomes from RPT & & & Expenses from RPT \\
sponsorship contract ( $€$ mln.): & & & provision of services $(€ \mathrm{mln}):$. & \\
recorded value & 10,00 & & recorded value & 2,50 \\
fair value & 8,00 & & fair value & 3,00 \\
FFP relevant income & $\mathbf{8 , 0 0}$ & & FFP relevant expense & $\mathbf{3 , 0 0}$ \\
downward adjustment & $\mathbf{2 , 0 0}$ & & upward adjustment & $\mathbf{0 , 5 0}$ \\
\hline
\end{tabular}

It clearly puts the problem of measuring the fair value of these transactions, especially for revenues. 
On the subject, the UEFA FFP Regulations refer to the traditional definition of the International Accounting Standards before the advent of the International Financial Reporting Standard 13 (IFSR 13): "Fair value is the amount for which an asset could be exchanged, or a liability settled, between knowledgeable willing parties in an arm's length transaction." (UEFA FFP Regulations, Annex X, par. E.7).

Today, the IFSR 13 on "fair value measurement", issued for making IAS converge with US GAAP, defines fair value as an "exit price": "Fair value (is) the price that would be received to sell an asset or paid to transfer a liability in an orderly transaction between market participants at the measurement date." (IFSR 13, par. 9) ${ }^{1}$.

IFSR 13 describes three different levels of fair value measurement (so called fair value hierarchy) that the vary from the most comparable and consistent level, so called level 1, to quoted prices (unadjusted) in active markets for identical assets and liabilities ... and the lowest priority to unobservable inputs" (IFSR 13, par. 72), in which "an entity shall develop unobservable inputs using the best information available in the circumstances, which might include the entity's own data" (IFSR 13, par. 89).

It is worth pointing out that the measurement at fair value before IFSR 13, which is the one in force for UEFA, presents high levels of uncertainty (Bell and Griffin, 2012; Christensen et al., 2012), in particular if operations are single events, where, even though one may consider the parties as "knowledgeable willing", it is really difficult to identify "an arm's length transaction". It is equally difficult to combine the objective availability of data offered by the external environment, especially from the market, with subjective management evaluations (Landsman, 2007). It is therefore necessary to support the validity of the measurement at fair value. It is important to improve a specific disclosure, both qualitative (Bratten et al., 2013) and quantitative (Bell and Griffin, 2012), and to identify specific frameworks also for transactions with related parties (Gordon et al., 2007). In these activity, the management has a specific responsibility to provide accurate information (Bell and Griffin, 2012).

In this regard, the UEFA document in application of FFP rules requires that "in the supplementary schedule for transactions with related parties, the licensee (the club) must disclose the prescribed information for all transactions with a related party, irrespective of whether or not there is an adjustment for the calculation of the break-even result." (UEFA FFP Solution Toolkit, par.

\footnotetext{
${ }^{1}$ According to IFSR 13, the market is: - "principal market for the asset or liability" (IFSR 13, par. 16.(a) - that is "the market with the greatest volume and level of activity for the asset or liability"), "or, in the absence of a principal market, the most advantageous market for the asset or liability" (IFSR 13, par. 16.(b) - that is "the market that maximises the amount that would be received to sell the asset or minimises the amount that would be paid to transfer the liability, after taking into account transaction costs and transport costs"). An active market is "a market in which transactions for the asset or liability take place with sufficient frequency and volume to provide pricing information on an ongoing basis".
} 
5.1.4) ${ }^{1}$. In a specific table, the club requesting license must clarify "a summary of the different types of evidence to support the deemed fair value of the transaction" (UEFA FFP Solution Toolkit, Appendix V, par. C.4).

Particular attention is paid by UEFA to revenues from sponsorship contracts. Revenues from "sale of sponsorship rights by a club to a related party" are the first example of "income transaction(s) with related party(ies) above fair value" .

Actually, the increase in sponsorships has been really enormous in the last decades. Sponsorship becomes one of the main source of revenues and it has different roots (Parks and Quarterman, 2003; Foster et al., 2006). Companies invest in sponsorship relationships for different objectives (Foster et al., 2006), therefore specific strategies (Shilbury et al., 1998) and models of strategic evaluation (Kase et al., 2010) are defined.

Investment in sponsorship are subject to accurate evaluating processes and models for the measurement of effectiveness (Foster et al., 2006), and efficiency (Cousens and Amis, 2003). However, it is still difficult to assess with certainty the actual return on investment in a sponsorship contract (Cousens and Amis, 2003).

Moreover, since the sponsorship contract normally underlies a synallagma $^{3}$, and therefore a mutually beneficial relationship between sponsor and sponsee), it may happen that the contract has different motivations, producing, on the operational point of view a dual benefit for the sponsee, rather than a synallagma, especially in the case of contracts with RPs.

In fact an opportunistic operation can hide behind a sponsorship contract of the PFC with a RP (which usually is an official, or institutional sponsor), viz. a real financing of the club by the sponsor. The contract with the RP may also underlie tax elusive purposes. The RP (sponsor) may in fact benefit from the tax accrued costs thanks to the invoice received from the club (sponsee). In turn, the club that produces structural economic losses, might reduce or

\footnotetext{
1“"The licensee must first disclose the following information: - the profit and loss account line that contains the related party transaction(s); - the amount of the transaction(s) as recorded in the annual financial statements and underlying accounting records ...; - the fair value of the transaction(s) ...; - brief explanatory comments about the transaction; - the difference (i.e. adjustment), if any, between the recorded value and the fair value. Secondly, for each account line containing one or more related party transactions the licensee must also disclose further details for each related party transaction, including: - the name of the related party ...; - a description of the nature of the transaction; - the amount of the transaction ...; - the fair value of the transaction; - the difference (i.e. adjustment), if any, between the recorded value and the fair value; and - a summary of the different types of evidence to support the deemed fair value of the transaction." (UEFA FFP Solution Toolkit, Appendix V, par. C.4).

${ }^{2}$ UEFA FFP Regulations, Annex X, par. B.1.j). Follow: "sale of corporate hospitality tickets, and/or use of an executive box, by a club to a related party", and the residual "any transaction with a related party whereby goods or services are provided to a club". "Monies received by a club from a related party as a donation" and "settlement of liabilities on behalf of the club by a related party" are specifically excluded from relevant incomes.

${ }^{3}$ Sponsorship is "a business agreement between two parties. The sponsor provides money, goods, services or know-how. In exchange, the sponsored party - individual, event or organization - offers rights and associations that the sponsor utilizes commercially" (Lagae, 2005).
} 
eliminate its losses without having any tax increase, through a "inflated value" sponsorship contract.

From an operational perspective, it is however difficult to determine the portion of the value to be considered as a revenue from "official or institutional sponsor" and the portion to be considered as a loan or an equity contribution from RP, for covering the losses of the club.

It follows that even if the controlling body of the "licensor" (namely the UEFA Club Financial Control Body - CFCB) "undertakes the assessment of the monitoring documentation and takes the appropriate decisions ..." (UEFA FFP Solution Toolkit, par. 2.1.11), it seems natural to imagine that the club requesting UEFA license will try to justify in any way the identity between fair and recorded value of the RPTs, with the consequent difficulties and possible controversies into the matter of such operations, namely for the fact that normally each RPT, as official or institutional sponsorship, represents a single event, for which it is not easy to identify neither an arm's length transaction, nor a "principal" or "most advantageous market".

In this regard, the analysis reported in table 2 shows that no PFC in Italy has reported RPTs (not just from sponsorship contracts) with recorded value different from the fair value. The same happens with emblazoned clubs in Europe, whose revenues have increased stratospherically also due to sponsorship contracts from RPs, enabling them to justify so many investments, thus trying to tackle the achievement of the economic objectives of FFP.

Despite leaving aside the analysis of the conditions for which revenues from services are recognized in accordance with IAS 18, it should be pointed out here that it would, at most, be possible to identify an "active market" in the field of technical sponsors (that sponsors through the partial or full payment of sporting equipments like goods or services), where a signaling indicator could be identified by the degree of sport competitiveness of teams. In this regard, the table 4 shows the correlation between the amount of technical sponsor contracts and the position reached in the Italian Serie A. The significant value of $\mathrm{R}^{2}$ (stabilized on significant values regarding both a single season, and the average amounts for three seasons) justifies the correlation and proves that the sport competitiveness awards the best teams, in a market of homogeneous goods such as those offered by technical sponsors.

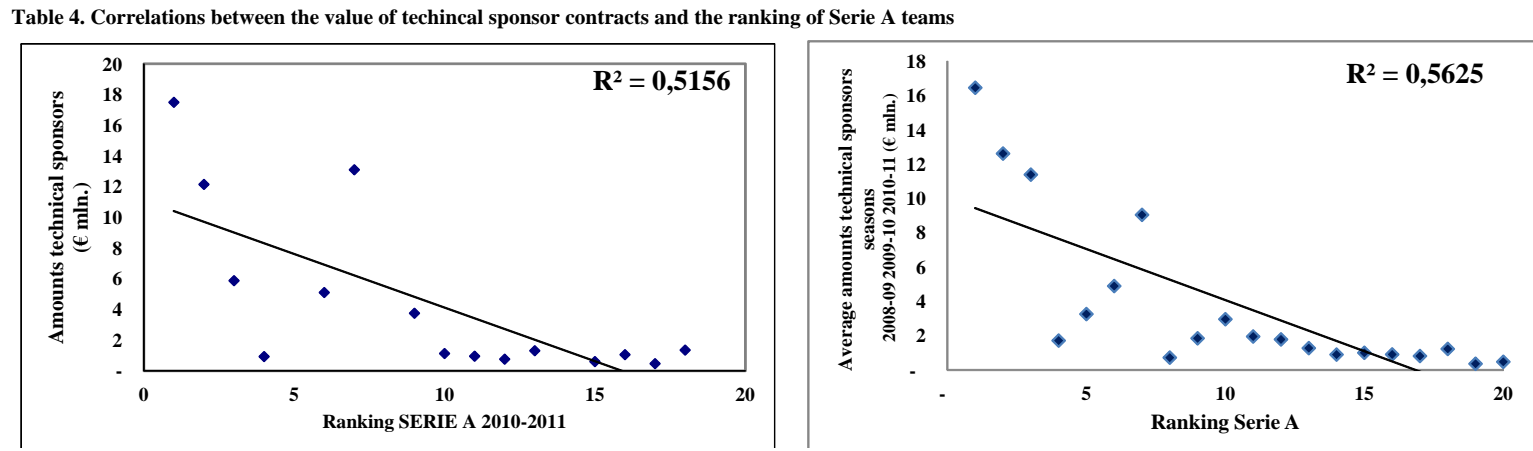


Therefore, in the case of technical sponsors it is possible to assume the existence of an active market, which describes values in an arm's length transaction, as well as in support of the hypothesis of a technical evaluation (according to the IFSR 13) at least of level 2 (that is the level in which "inputs are inputs other than quoted prices included within level 1 that are observable for the asset or liability, either directly or indirectly" - IFSR 13, par. 81).

The same considerations, however, cannot be formulated in the case of official or institutional sponsors that are RPs. In such cases, in fact, as shown in table 5, the values of the sponsorship contracts are not comparable in any way: each contract represents a singular case; for such transactions it is impossible to consider the existence of a market, neither homogeneous, nor active.

It is therefore evident that the procedures and the operations underlying the measurement at fair value of RPTs highlight some weaknesses, among which is the fact that each case should be decided on the merits, with the consequent high risk of treating similar cases differently. The consequence should be to undermine the effectiveness of the rules of FFP.
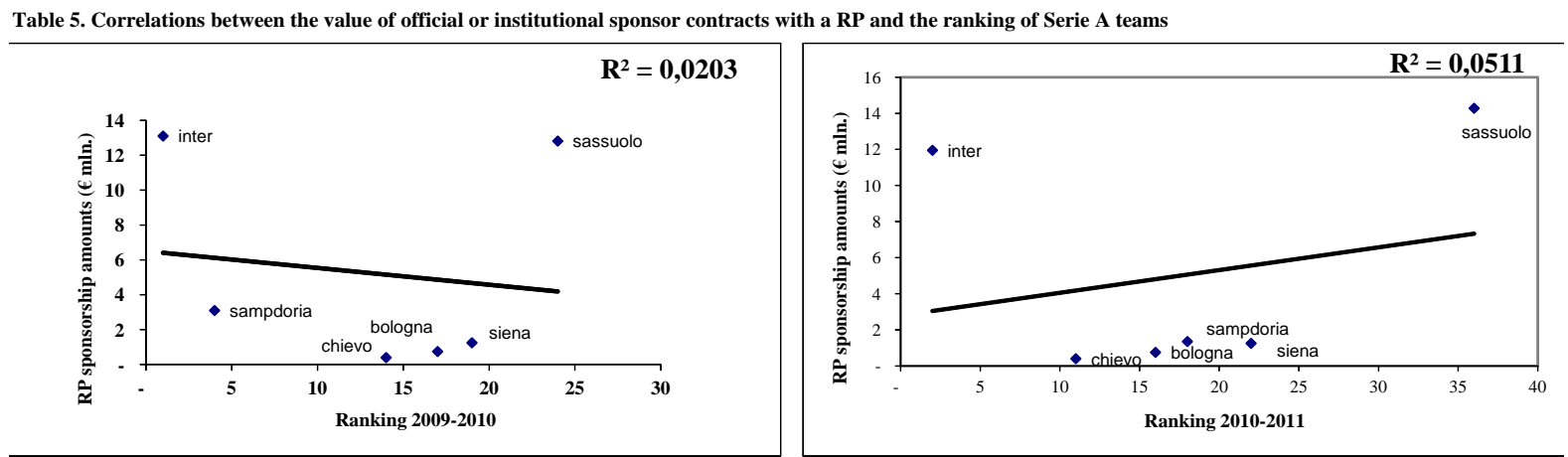

\section{Related Party Transactions and UEFA FFP: An Alternative Hypothesis to the Fair Value Measurement}

The above considerations lead to the opportunity to find an alternative for the fair value measurement of the RPTs.

Alternative measures do not infringe the international accounting standards and the fair value discipline, given that they have different purposes, compared to those of UEFA ${ }^{1}$. In other words, the fair value - as well as other rules of

\footnotetext{
1"Fair value is considered ... with respect to the two primary objectives of financial statements ..., namely (a) informativeness - to assist providers of capital in predicting, evaluating, and comparing the amounts, timing and uncertainty of future cash flows, and (b) stewardship - to assist in evaluating how efficient and effective managers have been in enhancing shareholders' value" (Ronen, 2008). Clubs must compete at sporting, economic and social environment level (Jacopin et al., 2010; Cincimino et al., 2012). With the FFP, UEFA tends to encourage clubs to operate on the basis of their own revenues, and also to compete as above. As a proof of the above, to encourage the social role of the soccer club, UEFA excludes from the relevant expenses, the expenditure on youth development and on community development activities. Also, to encourage clubs to invest in technical infrastructure, the excess proceeds on disposal of tangible fixed assets, like the stadium and training facilities not replaced, are excluded.
} 
international accounting standards - is recalled in the UEFA FFP Regulations as it may be useful (and instrumental) to the objectives which it aims to achieve through these rules.

The alternative proposal consists of an indicator using as a reference base the economical performances of all the clubs that have been obtained the UEFA license the sporting season preceding the reference one (common economic performances or CEP), as well as the specific economic performances which the club requesting the license gained in the reference sporting season (specific economic performances or SEP).

The reason to consider "common economic performances" (CEP) allows to treat all the clubs on an equitable basis, thus avoiding problems in the identification of specific criteria for their differentiation into categories. Moreover, UEFA has already dealt with the acceptable deviation in the same way for all the clubs, regardless of their different performances. (art. 61 UEFA FFP Regulations). The reason to consider all the clubs that have requested UEFA license the season preceding the reference one allows to give an orientation to the clubs wishing to obtain the license in the subsequent season, making them aware previously of the value that would be recognized by UEFA.

The CEP must also assume stable values, which can be done also by using a high number of data concerning numerous clubs. It must also avoid the possibility of being affected by possible specific "cartel agreements" between clubs. For example, an exponential increase in the value of sponsorship contracts from RPs, although they are not evaluable at fair value, could certainly justify as much exponential elevations of the values that UEFA will consider as benchmarks. As a paradoxical consequence clubs might have found, once again in the football world, a way to dribble economic effective rules. The value of the CEP should eventually enable to reach a compromise between UEFA and the most emblazoned PFCs, that because of the FFP rules risk of losing their sporting competitiveness, and may at any time threaten their renunciation in European competitions, to create a specific organization in which to compete.

Specific economic performance gained by the individual clubs (SEP), should also be taken into account, stimulating at the same time the production of operating revenues other than those produced by RPTs.

For the above purpose, in the opinion of the writer each club might have admitted, as FFP "relevant incomes" from RPTs, all RPT revenues resulting from the following formula ${ }^{1}$ :

$$
R_{R P T} F F P C l u b(a)=x R_{R P T(a)} \cdot \frac{1}{n} \cdot \sum_{i=1}^{n} \frac{R_{o(i)}-R_{R P T(i)}}{R_{o(i)}}+(1-x) R_{R P T(a)} \cdot \frac{R_{o(a)}-R_{R P T(a)}}{R_{o(a)}}
$$

where:

\footnotetext{
${ }^{1}$ Obviously they are not included in revenues from RPT those expressly excluded by UEFA FFP Regulations. In this regard see UEFA FFP Regulations, Annex X, par. B.1.j).
} 
$\mathbf{R}_{\text {RPT }}$ FFP Club $(\boldsymbol{a})$ are the FFP "relevant incomes" from RPTs of Club (a) $\operatorname{Club}(a)$ represents the club requesting the UEFA license

Club( $i)$ represents the clubs $(i)$ that in the previous season have obtained UEFA license

$\boldsymbol{x}$ is the percentage of RPT revenues earned by the Club $(a)$ in the reference season, which should be attributed to the value of CEP

$\boldsymbol{1 - x}$ is the "complementary" percentage of RPT revenues earned by the Club $(a)$ in the reference season, which should be attributed to the value of SEP

$\mathbf{R}_{\mathbf{R P T}}(\boldsymbol{a})$ are the RPT revenues earned by the Club $(a)$, taken from the financial statement of the Club $(a)$ of the reference season

$\mathbf{R}_{\mathbf{0}}(\boldsymbol{a})$ are the operating revenues (including profits, or revenues, on disposal of player registrations, respectively if the Club $(a)$ applies capitalisation and amortisation methodology, or revenue and cost methodology, for player registration) earned by the Club $(a)$, taken from the financial statement of the Club $(a)$ of the reference season

$i$ represents the " $n$ " clubs that have been obtained UEFA license the previous season for which the indicator is effective

$\mathbf{R}_{\mathbf{R P T}}(i)$ are the RPT revenues earned by each Club (i), accrued in the season preceding the reference one, taken from the financial statements of each Club (i) of the season preceding the reference one

$\mathbf{R o}(i)$ are the operating revenues (including profits, or revenues, on disposal of player registrations, respectively if the Club $(i)$ applies capitalisation and amortisation methodology, or revenue and cost methodology, for player registration) earned by each Club (i) accrued in the season preceding the reference one, taken from the financial statements of each Club $(i)$ of the season preceding the reference one $\mathbf{n}$ is the total number of Clubs $(i)$ that have been obtained UEFA license UEFA the season preceding the reference one.

Taking into consideration that:

$$
\frac{1}{n} \cdot \sum_{i=1}^{n} \frac{R_{o(i)}-R_{R P T(i)}}{R_{o(i)}} \text { is CEP, and } \frac{R_{o(a)}-R_{R P T(a)}}{R_{o(a)}} \text { is SEP, }
$$

the formula can be represented as follows:

$$
R_{R P T} F F P C l u b(a)=x R_{R P T(a)} \cdot C E P+(1-x) R_{R P T(a)} \cdot S E P
$$

Empirical evidences (table 6) show that the value of CEP:

a. tends to decrease as higher is the number of Clubs $(i)$ that increase their amount of $\mathrm{R}_{\mathrm{RPT}}(i)$ (hypotheses $\mathrm{X}$ or $\mathrm{Y}$ of 10,15 or 20 clubs)

b. tends to decrease, and at least to stabilize, in case of significant increases in the $\mathrm{R}_{\mathrm{RPT}}(i)$ values (comparing hypotheses $\mathrm{X}$ - lower $\mathrm{R}_{\mathrm{RPT}}(i)$ - and $\mathrm{Y}$ - more $\mathrm{R}_{\mathrm{RPT}}(i)$ )

c. assumes higher values, for equal increments of $\mathrm{R}_{\mathrm{RPT}}(i)$, in the hypothesis of increments of $\mathrm{R}_{\mathrm{o}}(i)$, (comparing hypotheses $\mathrm{W}$ - lower $\mathrm{R}_{\mathrm{o}}(i)$ - and $\mathrm{Z}$ - more $\mathrm{R}_{\mathrm{o}}(i)$ ). This can also represent a leverage effect, in favor of the admissibility of 
RPT revenues due to higher income from other operations, not from RPs. Moreover, the increase in operating revenues is in line with what is desired by UEFA in terms of actual economic rebalancing of profits and losses.

The value CEP could represent a compromise between UEFA and the PFCs "assisted" by high amounts of capital. Indeed, this value would tend to stabilize at high amounts, and for this reason, with CEP stabilized value, the FFP relevant incomes from RPTs would increase due to the increasing in absolute value of the relevant sponsorship contracts. However, also the capital invested in the football sector should increase, and this would be a benefit in the sector.

The SEP value will be as higher as greater will be the incidence of other operating revenues on total revenues. However, other conditions being equal, high values of $\mathrm{R}_{\mathrm{RPT}}(a)$ would substantially reduce the value of SEP.
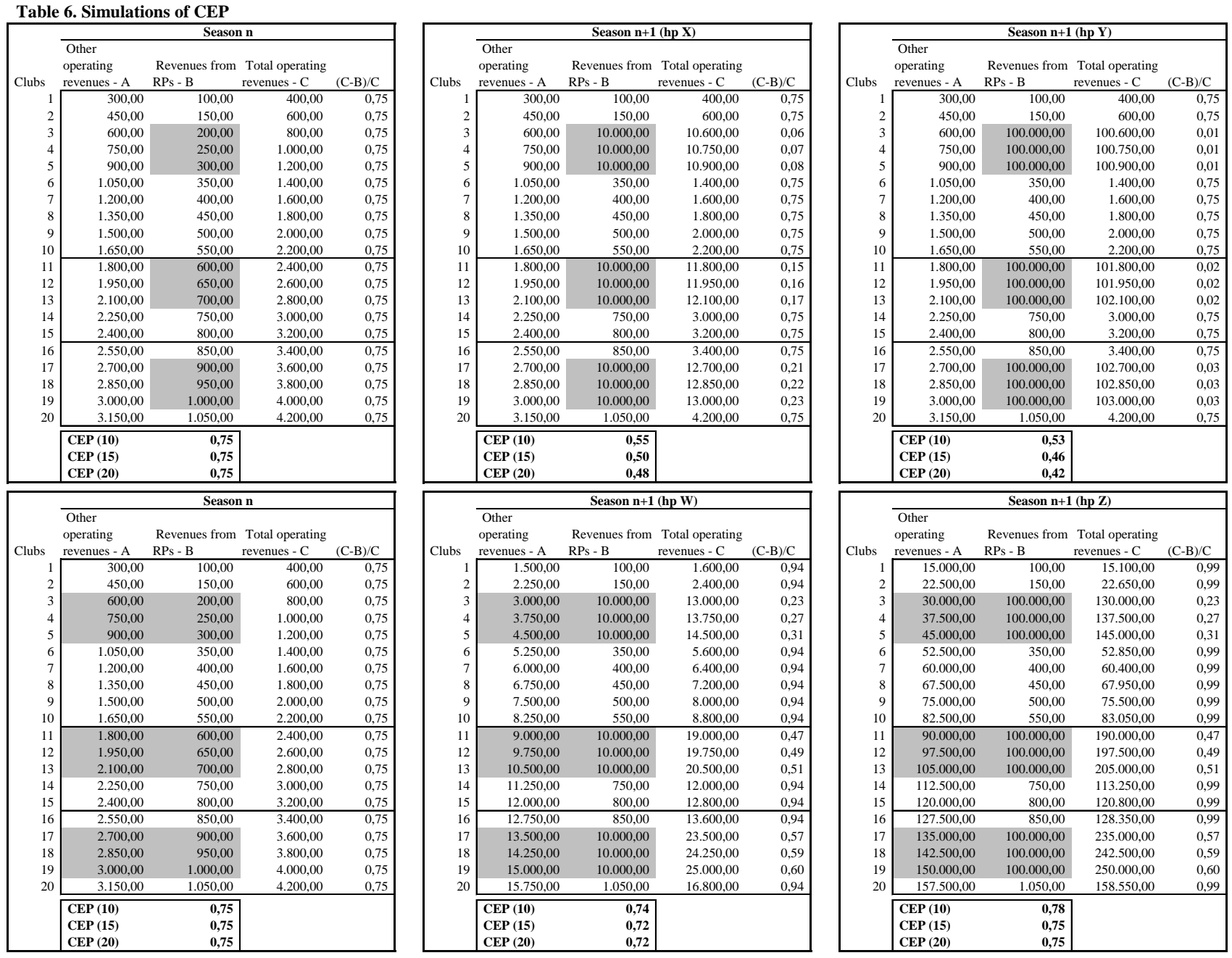

The value of $x$ in the formula thus has an important role.

The value of $x$ must be specifically defined, and represents the "cursor" in the share of $\mathrm{R}_{\mathrm{RPT}}(a)$ to be submitted to the CEP value and, by difference, the remaining portion to be submitted to the value of SEP. In this regard could also 
be used a "threshold amount", beyond which intervenes the SEP value. For instance, $\mathrm{R}_{\mathrm{RPT}}(a)$ less than or equal to $€$ mln 10 undergo to the value of CEP; $\mathrm{R}_{\mathrm{RPT}}(a)$ in excess of $€$ mln 10 , are computed for $x$ on the basis of the value of CEP, for $1-x$ on the basis of the value of SEP.

By virtue of the above indicator, for the $\operatorname{Club}(a)$, the difference between $\mathrm{R}_{\mathrm{RPT}}(a)$ and the FFP relevant incomes from RPTs of Club $(a)$ represents the downward adjustment.

Also a percentage of the mentioned difference could be invested in social activities. In a similar way the costs from RPT may handled.

\section{Conclusions}

Intervening on economic equilibriums of PFCs - leveraging on the revenues that they are able to produce rather than on funding they can get - and providing at the same time guidance on how to orient their investments, represents a great challenge for the UEFA. The system of FFP rules implemented for such purposes is also effective for the fact that it was prepared with the support of football clubs, but it is "accepted" by the most emblazoned clubs because of the capital that their owners, or related parties, are able to invest, instead of the revenues that they accrue.

In this context, the conversion of loans in commercial transactions with related parties may represent at the same time a dribbling of the FFP rules and also a tax advantage for the RPs.

For this reasons, linking the measurement of the RPTs to the principles of international accounting standards (even if effective for the purposes for which they are issued), and then at fair value, represents a potential risk, because it would be necessary to discuss into the matter of each operation, with the consequent possibility to treat similar cases differently, and to enable controversies that would not benefit in any way to European sporting competitions.

The alternative proposal for measuring revenues from RPTs discussed and presented in this contribution has the advantage of allowing a measurement of RPTs for the purposes of FFP, based solely on quantitative data (economic performances of great sample of PFCs, and economic performances of the club requesting the license), and also encourages the production of no RPTs operating revenues, both at system and at individual club level, which is one of the principal reasons why UEFA implemented FFP, that is the raising of managerial skills of European clubs.

\section{References}

Bell, T.B. \& J.B. Griffin (2012). 'Commentary on Auditing High-Uncertainty Fair Value Estimates.' Auditing: A Journal of Practice \& Theory 31(1): 147-155. 
Berglöf, E. \& A. Pajuste (2005). 'What do Firms Disclose and Why? Enforcing Corporate Governance and Transparency in Central and Eastern Europe.' Oxford Review of Economic Policy 21(2): 178-197.

Bratten, B, L. Milici Gaynor, L. McDaniel, N.R. Montague \& G.E. Sierra (2013). 'The Audit of Fair Values and Other Estimates: The Effects of Underlying Environmental, Task, and Auditor-Specific Factors.' Auditing: A Journal of Practice \& Theory 32(Supplement 1): 7-44.

Cain, D.M., G. Loewenstein \& D.A. Moore (2005). 'The Dirt on Coming Clean: Perverse Effects of Disclosing Conflicts of Interest.' Journal of Legal Studies 34(1): 1-25.

Cheung, Y.L., Y. Qi, P. Raghavendra Rau \& A. Stouraitis (2009). 'Buy High, Sell Low: How Listed Firms Price Asset Transfers in Related Party Transactions.' Journal of Banking \& Finance 33(5): 914-924.

Christensen, B.E., S.M. Glover, \& D.A. Wood (2012). 'Extreme Estimation Uncertainty in Fair Value Estimates: Implications for Audit Assurance.' Auditing: A Journal of Practice \& Theory 31(1) 127-146.

Cincimino, S., S. Tomaselli \& F. Carini (2012) 'The Model of Governance of the Professional Football Sector in Italy: A Critical Analysis.' Journal Of Sport Sciences And Law V(3-4): 111-128.

Cousens, L. \& J. Amis (2003). 'Sport and Sponsorship.', In L. Trenberth (ed.), Managing the Business of Sport, 229-249. Palmerston North, New Zealand: Dunmore Press.

Foster, G., S.A. Greyser \& B. Walsh (2006). The Business Of Sports: Text and Cases On Strategy And Management. Melbourne: Thomson.

Gordon, E.A., E. Henry \& D. Palia (2004). 'Related party transactions and corporate governance.' Advances in Financial Economics 9: 1-27.

Gordon, E.A., E. Henry, T. J. Louwers \& B.J. Reed (2007). 'Auditing Related Party Transactions: A Literature Overview and Research Synthesis.' Accounting Horizons 21(1): 81-102.

Handfield, R.B. \& D.L. Baumer (2006). 'Managing Conflict of Interest Issues in Purchasing.' Journal of Supply Chain Management 42(3): 41-50.

Hasseldine, J., A.I. Salamab \& J.S. Toms (2005). 'Quantity Versus Quality: The Impact of Environmental Disclosures on the Reputations of UK Plcs.' The British Accounting Review 37(2): 231-248.

Hutton, A.P. \& P.C. Stocken (2009). 'Prior Forecasting Accuracy and Investor Reaction to Management Earnings Forecasts.' Social Science Research Network, working papers series. Available at: http://papers.ssrn.com/sol3/papers.cfm? abstract_id=817108 [1 July 2013].

International Accounting Standards Board (IASB). (2009). International Accounting Standard 24 - Related Party Disclosures (2009). London: IASB.

International Accounting Standards Board (IASB). (2011). International Financial Reporting Standard 13 - Fair Value Measurement (2011). London: IASB.

Jacopin, T., K. Kase, \& I. Urrutia (2010). 'Value Creation and Performance Criteria for Sport Entities.' In S. Gomez, K. Kase \& I. Urrutia (eds.), Value Creation and Sport Management, 22-59. Cambridge: Cambridge University Press.

Kase, K, I. Urrutia \& C. Martì (2010). 'Strategic Evaluation of Sponsorship and Patronage.' In S. Gomez, K. Kase \& I. Urrutia (eds.), Value Creation and Sport Management, 220-228. Cambridge: Cambridge University Press.

Koch, C. \& C. Schmidt (2010). 'Disclosing Conflicts of Interest - Do Experience and Reputation Matter?' Accounting, Organizations and Society 35(1): 95-107. 
Lagae, W. (2005). Sports Sponsorship and Marketing Communications: A European Perspective. Harlow, England ; New York: Financial Times Prentice Hall.

Landsman, W.R. (2007). 'Is Fair Value Accounting Information Relevant and Reliable? Evidence from Capital Market Research.' Accounting and Business Research 37(Supplement 1): 19-30.

McCahery J.A. \& E.P.M. Vermeulen (2011). 'Mandatory Disclosure of Blockholders and Related Party Transactions: Stringent Versus Flexible Rules.' Social Science Research Network, working papers series. Available at: http://papers.ssrn.com/ sol3/papers.cfm?abstract_id=1937476 [3 July 2013].

Michelon, G. (2011). 'Sustainability Disclosure and Reputation: A Comparative Study.' Corporate Reputation Review 14(2): 79-96.

Organismo Italiano di Contabilità (OIC). (2004,October). Italian Accounting Principle 1 (OIC 1). Italy: OIC

Organismo Italiano di Contabilità (OIC). (2005,May). Organismo Italiano di Contabilità-Appendix to Italian Accounting Principle OIC 1. Italy: OIC

Organismo Italiano di Contabilità (OIC). (2010,March). Appendix to Italian Accounting Principle OIC 12. Italy: OIC

Parks J.B. \& J. Quarterman (2003). Contemporary Sport Management, $2^{\text {nd }}$ ed. Champaign, IL: Human Kinetics.

Ronen, J. (2008). 'To Fair Value or Not to Fair Value: A Broader Perspective.' Abacus: A journal of accounting, finance and business studies 44(2): 181-208.

Shilbury, D., S. Quick \& H. Westerbeek (1998). Strategic Sport Marketing. Sydney: Allen and Unwin.

Toms, J.S. (2002). 'Firm Resources, Quality Signals and the Determinants of Corporate Environmental Reputation: Some Uk Evidence.' The British Accounting Review 34(3): 257-282.

Union of European Football Associations (UEFA). (2012). UEFA Club Licensing and Financial Fair Play Regulations. Edition 2012. Nyon: UEFA.

Union of European Football Associations (UEFA). (2013). UEFA Club Licensing and Financial Fair Play CL/FFP IT Solution Toolkit. Edition 2013. Nyon: UEFA.

Wong, T.J. \& M. Jian (2003). 'Earnings Management and Tunneling through Related Party Transactions: Evidence from Chinese Corporate Groups', Social Science Research Network, working papers series. Available at: http://papers.ssrn.com/ sol3/papers.cfm?abstract_id=424888 [3 July 2013]. 